\title{
Seawater iron isotopes as a new tool to characterize the physicochemical speciation of dissolved iron: Southern East Pacific Rise case study
}

\author{
JESSICA N. FITZSIMMONS ${ }^{1}$, JANELLE M. STEFFEN ${ }^{1}$, \\ Brent A. SuMmers ${ }^{2}$, Tim M. CONWAY ${ }^{2}$, ROBERT M. \\ SHERRELL $^{3}$ \\ ${ }^{1}$ Department of Oceanography, Texas A\&M University, \\ College Station, TX, 77843, USA (*Correspondence: \\ jessfitz@tamu.edu)
}

${ }^{2}$ College of Marine Sciences, University of South Florida, St. Petersbug, FL USA.

${ }^{3}$ Department of Marine \& Coastal Sciences, Rutgers Universty, New Brunswick, NJ USA.

The bioavailability and scavenging fate of dissolved iron $(\mathrm{dFe})$ in the ocean is dependent on its physicochemical speciation, yet there are no analytical methods that reveal the general character of marine $\mathrm{dFe}$, especially basic differentiation of organically-complexed $\mathrm{Fe}$ from tiny nanoparticulate phases. Here, we propose that $\mathrm{Fe}$ isotopes can be used to derive this speciation, so long as the system meets certain assumptions.

We demonstrate how seawater $\mathrm{dFe}$ isotopes can reveal the physicochemical speciation of dFe using the case study of the Southern East Pacific Rise (SEPR) non-buoyant hydrothermal plume at $15^{\circ} \mathrm{S}$. We objectively assign $\mathrm{Fe}$ isotope signatures for each of three $\mathrm{Fe}$ species that are present in the hydrothermal plume: background organic dFe-ligand (FeL) complexes, hydrothermal organic dFe-ligand complexes, and Fe oxyhydroxide nanparticles. We then apply these isotope signatures to an isotope mass balance model, which also includes the soluble and colloidal Fe concentrations to reveal the complete physicoehcmial speciation of $\mathrm{dFe}$ in this plume.

We find that Fe oxyhydroxide nanparticles are released from the SEPR in both the larger colloidal and, surprisingly, also smaller soluble size fractions. The nanoparticles are supplied in high concentration but are lost quickly from the plume. In contrast, hydrothermal FeL complexes form in the juvnile plume in the smaller soluble size fraction and aggregate into the larger colloidal size fraction down-plume. Thus, overall, the dFe in this SEPR plume does not appear to be conserved, since $\mathrm{Fe}$ oxyhydrixide nanoparticles are rapidly lost from both the soluble and colloidal size fractions. Assessments of bulk physicoehcmial speciation, such as this one, are important in order to constrain global iron biogeochemical models, especially for internal cycling rates such that are difficult to measure directly. 